\title{
House Management System with Real and Virtual Resources: Energy Efficiency in Residential Microgrid
}

\author{
Gabriel Santos, Filipe Fernandes, Tiago Pinto, Marco Silva, Omid Abrishambaf, Hugo Morais, Zita Vale \\ GECAD - Research Group on Intelligent Engineering and Computing for Advanced Innovation and Development, \\ IPP - Polytechnic of Porto, \\ Porto, Portugal \\ \{gajls, fijgf, tmcfp, marsi, ombaf, hugvm, zav\} @isep.ipp.pt
}

\begin{abstract}
The reduction of the greenhouse gas emissions is a priority all around the globe. The investment on renewable energy sources is contributing for new opportunities in the context of the smart grids and microgrids. Recent advances are transforming the consumer into a prosumer, being able to adapt the consumption depending on its own generated power, and selling the surplus or buying the missing power. In this context, home management systems are emerging as an effective means to support the management of energy resources in the context of communication between functions/devices of a smart home. This paper presents a new agent-based home energy management approach, using ontologies to enable semantic communications between heterogeneous multi-agent entities. The main goal is to support an efficient energy management of end consumers in the context of microgrids, obtaining a scheduling for both real and virtual resources. A case study is presented, which simulates a 25-bus microgrid that includes a laboratorial controlled house (with real and simulated resources), which is managed by the proposed energy management system.
\end{abstract}

Keywords-Demand Response, Distributed Energy Resources, Energy Efficiency, House Management, Ontologies.

\section{INTRODUCTION}

The investment on renewable energy sources has an important role in the reduction of the greenhouse gas emissions, reducing the dependency on limited fossil fuels [1]. The directives defined by European Union and called H2020, include several incentives for reducing greenhouse gas by $20 \%$, increasing the penetration of renewable energy sources by $20 \%$ and the energy efficiency by $20 \%$ by 2020 [2]. During the last years, Portugal also has been investing on renewable energy sources being in agreement with recent changes in the legislation to increase energy efficiency [3]. This new context makes it possible for consumers, in Portugal, to use their own generation, creating new opportunities, as they are no longer limited to selling all the generated power and paying for their full consumption [4].

In the context of the smart grids and microgrids a new opportunity emerges and the consumer becomes a prosumer, being able to adapt the consumption depending on their own generated power, selling the surplus power or buying the missing power, according with the needs in each moment [5]. The new paradigm shows the consumer with an active participation in the grid environment, changing its own use habits due to the intensive use of renewable energy sources of intermittent nature: affecting the balance between consumption and generation [6]. In this context, a smart home should include three main elements: internal communication network, intelligent control systems, and home automation. The smart home contemplates a central controller and the electrical appliances being a remote control interface to communicate between to functions. The communication between users and devices through internet or mobile messages [7]. Moreover, house management systems should be able to effectively manage consumption, distributed generation and the participation in Demand Response (DR) events, such as dynamic energy tariffs [8]. Also, house management system should consider a complex environment with connection between smart devices and electrical appliances providing different smart functions. It is important an effective manage system with interaction with user. The management system with a hierarchical for each model of the smart home allow the development of a context-aware services [9]. However, an effective communication for a complex smart home system with complex functionalities and strategies, and with several types of energy resources in the context of smart grids is needed.

The present paper focuses in a new approach of the house energy management, using ontologies to enable semantic communications between heterogeneous multi-agent entities, to support an efficient energy management of end consumers. The house management system operates according to a multiagent based smart grid simulation platform, which uses an Energy Resources Management (ERM) model that includes DR programs, electric vehicles and several types of renewable energy sources. The main goal is to obtain a scheduling for real and virtual resources of the house, using ontologies for the communications between the heterogeneous agents present in the house management system: for actuators through the Programmable Logic Controller (PLC), for the optimization algorithms and house manager, that also communicates with the grid manager. The main contribution of the paper is, thereby, the restructuring of the SCADA House Intelligent 
Management (SHIM) platform [10] with the inclusion and application of ontologies to promote the interoperability between heterogeneous agent based systems, contributing to a more efficient management system, i.e., for a energy efficiency system.

After this introductory section, the multi-agent simulation platform is presented in Section II. Section III describes the energy management platform of house consumer. Section IV presents the case study and the main results, discussing the advantages of the proposed approach. The main contributions of this work are presented in Section V.

\section{Multi-Agent Simulation IN SMART GRID OPERATION}

Accommodating the integration of the fast growing renewable energy sources penetration in the power system is a critical and urgent problem that must be addressed by a distributed approach [11]. Simulation combined with distributed artificial intelligence is growing as an adequate form to study the evolution and coordination of smart grid. Modelling the smart grid environment using Multi-Agent Systems (MAS) enables model enlargements to include new players and allows studying and analyzing both the individual and internal performance of each distinct player; as well as the global and specific interactions between all the involved players [12]. The Multi-Agent Smart Grid Simulation Platform (MASGriP) has been developed in GECAD to simulate the operation of smart grid and microgrids. MASGriP uses ERM for scheduling the smart grid; and also a SHIM model (presented in Section III). The MAS and ERM platforms are presented and summarized in this section.

The several platforms are set up and executed using TOOCC (TOOls Control Center). TOOCC provides the independent usage of algorithms and tools for scenarios analysis. It allows, not only defining the models and setting up all the necessary parameters and definitions, but also executing the system in any domain machine without the need for having all necessary software installed in each machine. Rather, TOOCC communicates with the server that contains all the required software and algorithms, and guarantees that everything is available for agents, as needed. This approach also enables the execution of algorithms and the use of models from external entities without the need for installing the required software and setting up all definitions locally.

\section{A. MASGriP platform}

MASGriP models the internal operation of smart grid [12], considering all the typically involved players, which are modelled by software agents. The considered players include different types of operators, aggregators, and several energy

\footnotetext{
The research leading to these results received funding from: the European Union's Horizon 2020 research and innovation programme under project EUREKA - ITEA2 Project FUSE-IT (ITEA2-13023).
}

resources, such as several types of consumers (e.g. industrial, commercial, residential), different types of producers (e.g. wind farms, solar plants, cogeneration units), electric vehicles with vehicle-to-grid capabilities, among others. Additionally, some agents are directly connected to physical installations, enabling an automatic management of the associated resources. The physical installations consist of four spaces: three campus buildings of GECAD, and a laboratorial controlled house: SHIM [10], which contains a large set of different loads, normally used in a common house. MASGriP uses real-time simulation to complement simulations with the analysis of the methods impact in the network lines [10], [12]. MASGriP uses several intelligent methodologies to support agents operation at different levels. Communications between MASGriP agents, which enable them executing the algorithms, such as ERM and SHIM, are supported by ontologies, as presented in section III.

\section{B. ERM platform}

The ERM methodology optimizes the distributed energy resources that are ayailable in a smart grid managed by a Virtual Power Player (VPP). It considers all the available resources: distributed generation, electric vehicles, storage units, and DR, and supports the negotiation with external players. The goal is to satisfy demand aiming at obtaining the maximum profit. The ERM is executed in three phases: dayahead, hour-ahead and real-time scheduling [13], [14].

The first phase of the ERM is to perform the day-ahead resources scheduling, considering all available resources and the day-ahead forecast for each of the involved resources. In the second phase, all the renewable resources and the consumption forecasts for each period are updated (one hour periods) through the forecast hour-ahead, and then all the resources managed through the hour-ahead scheduling are adjusted taking into account the results of the day-ahead scheduling and the scheduling results of the previous hour. In the third phase the resources are updated, being optimized for the next five minutes. After the real-time forecast, the optimal scheduling process is executed for the following 5 minutes taking into account the results of the hour-ahead scheduling, the results of the previous 5-minutes scheduling and the forecasted values for the following 5 periods of 5 minutes. The VPP operator, which manages the network and its distributed energy resources, is able to sell electricity, obtaining additional incomes, as scheduled by the distributed energy resources management algorithm, with ERM scheduling formulation in [13], [14].

\section{INTELLIGENT HOUSE MANAGEMENT IN MASGRIP CONTEXT}

SHIM is a testbed platform in the context of intelligent house management with the main goal of testing, simulating, 
and validating new algorithms and methodologies. The new approach presented in the paper concerns the use of ontologies to enable semantic communications between heterogeneous multi-agent entities, to support an efficient energy management of the house energy management.

\section{A. SHIM platform}

SHIM is composed of different modules that are grouped into three different parts: the Data acquisition, the Actuators, and the Intelligent Applications. The structure of the SHIM platform is then presented in Fig. 1. More detailed information about SHIM platform and structure used for house management is presented in [10]. The intelligent applications part of the SHIM system has the resources management module to manage the energy consumption in a domestic consumer. The module activation is processed by the event trigger and, in the first step, all the necessary data is collected for the present context: the resources priority, the power consumption limits, the resources characteristics and the actual status of each resource (lights, HVAC, refrigerator, etc...).

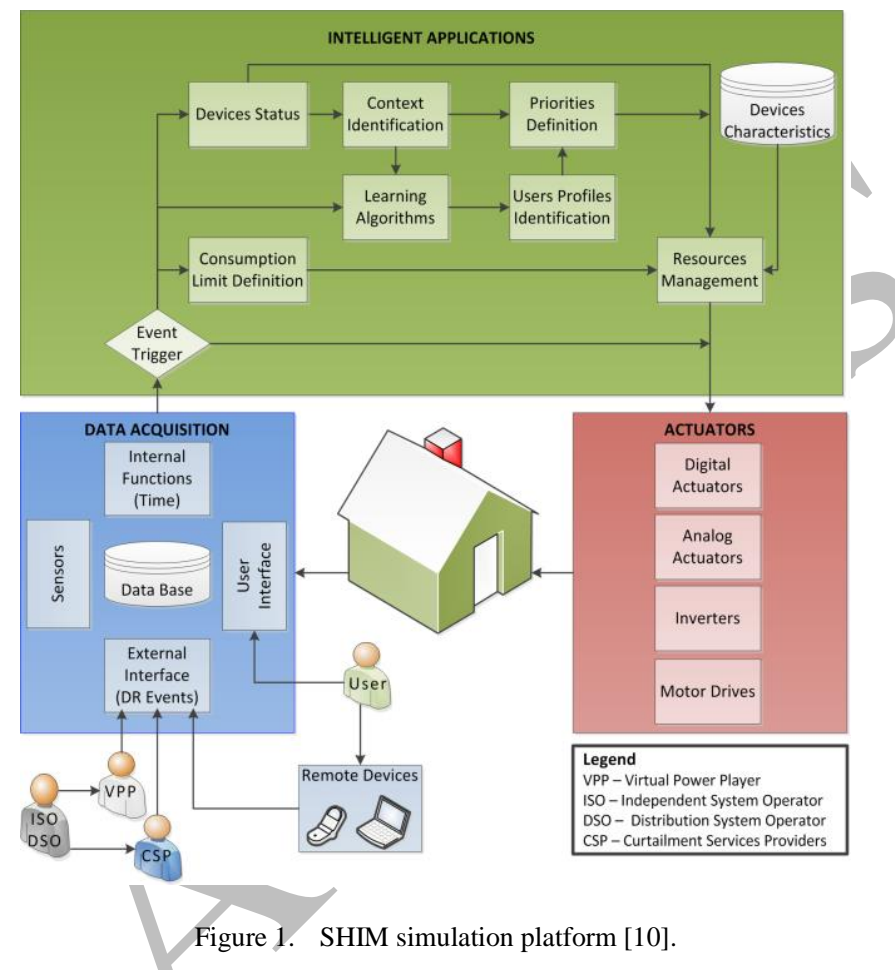

An optimization algorithm tries to minimize the impact of the loads curtailments that depends of the loads and ERM status. The priority values change between 0 and 10 , factor 10 being used for lower priority resources, and factor 0 for the highest priority resources. The detailed information about of optimization method considering the loads is presented in [10]. The objective function and respective constrains is presented below. Equation (1) presents the objective function to determine the loads that should continue in service. Equation (2) determines the power balance and (3) and (4) show the maximum and minimum limits of respective loads and the decision is imposed by the binary variable $x_{\text {Load }}$.. This last constrains depends of the load type. If the load is discrete (On/Off), variable $P_{\text {Load }}^{\text {Max }}$ is equal to $P_{\text {Load }}^{\text {Min }}$.

$$
\begin{aligned}
& \text { Minimize } f=\min \\
& \left\{\sum_{\text {Load }=1}^{\text {nLoad }} \lambda_{\text {Load }} \times P_{\text {Load }}+\lambda_{\text {Down }} \times \operatorname{Reg}_{\text {Down }}-\lambda_{U P} \times \operatorname{Reg}_{U p}\right\} \\
& P_{\text {Limit }} \geq \sum_{\text {Load }=1}^{n \text { Load }} P_{\text {Load }}+\operatorname{Reg}_{\text {Down }}+P_{\text {FixedLoads }}-\operatorname{Reg}_{U p} \\
& P_{\text {Load }} \leq P_{\text {Load }}^{\text {Max }} \times x_{\text {Load }} \\
& P_{\text {Load }} \geq P_{\text {Load }}^{\text {Min }} \times x_{\text {Load }} \\
& \text { where } \\
& \lambda_{\text {Load }} \quad \text { Load priority } \\
& \lambda_{\text {Down }} \quad \text { Regulation down priority } \\
& \lambda_{U p} \quad \text { Regulation up priority } \\
& \text { Load Load index (ID) } \\
& \text { nLoad Maximum number of loads } \\
& P_{\text {Load }}^{\operatorname{Max}} \quad \text { Maximum load consumption [W] } \\
& P_{\text {Load }}^{\text {Min }} \quad \text { Minimum load consumption [W] } \\
& P_{\text {FixedLoads }} \text { Total consumption of non-controlled loads } \\
& P_{\text {Limit }} \quad \text { Power limit for the total consumption [W] } \\
& P_{\text {Load }} \quad \text { Power consumption of load [W] } \\
& \operatorname{Reg}_{\text {Down }} \quad \text { Power regulation down [W] } \\
& \operatorname{Reg}_{U p} \quad \text { Power regulation up [W] } \\
& x_{\text {Load }} \quad \text { Load binary variable }
\end{aligned}
$$

\section{B. Ontologies for Interoperability}

MAS in the power system's domain are usually developed with their own specific ontologies [15]. The use of ontologies for the interoperability between heterogeneous systems enables full knowledge exchange, taking full advantage of 
these systems' functionalities. To reuse existing ontologies is usually a requirement for systems' interoperability [16]. Unfortunately, for very specific systems, such as the ones approached in this paper (ERM and SHIM), almost all of the ontologies have to be developed from scratch. Fig. 2 illustrates the hierarchy of the ontologies.

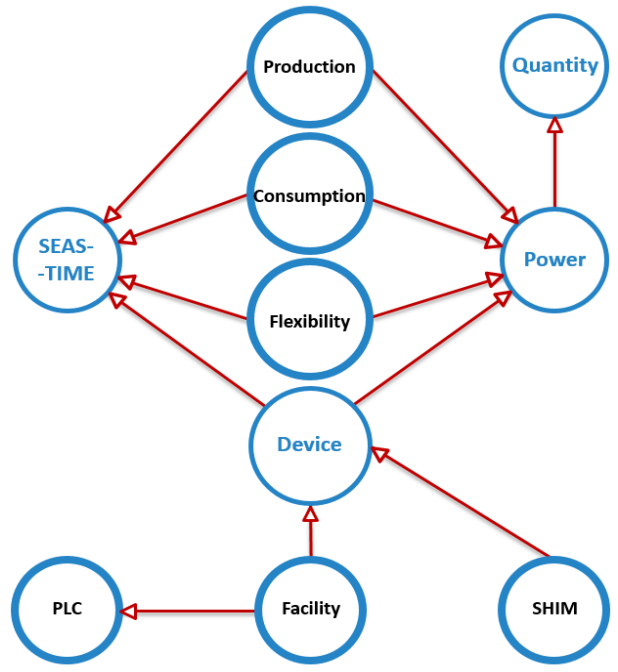

Figure 2. Ontologies for the Interoperability of Energy Efficiency Systems

In this paper are focused on the main ontologies. The remaining ontologies only define knowledge modules that are reused by the main ontologies. The main Ontologies used by our systems are: the (i) PLC Ontology; (ii) Facility Ontology; (iii) SHIM Ontology; and the (iv) Production, (v) Consumption and (vi) Flexibility ontologies, with following description:

- PLC Ontology: enables the interoperability of any Facility Manager Agent with PLCMAS, a multi-agent system developed with the purpose of controlling physical devices connected to any PLC. This ontology defines a PLC including its resources characteristics about a light, a window, a HVAC, etc.;

- Facility Ontology: defines an abstract facility, i.e. a building, a house or an office; its divisions (Room, Kitchen, Living Room, etc.) and devices per division. This ontology represents the main concepts of the Facility Manager Agent knowledge base;

- $\quad$ SHIM Ontology: allows any Facility Manager Agent to request for a SHIM Optimization Agent to the OptiMAS, a multi-agent system developed with the intention of making available different types of optimization algorithms in the field of Power Energy Systems. This agent runs the SHIM optimization after receiving the DR event from the VPP;
- Production, Consumption and Flexibility ontologies: represents the communications between the VPP and its aggregated players, namely consumers, producers and prosumers. Each aggregated player informs, periodically, the VPP about their consumption and/or production; using respectively the Consumption and Production ontologies. After the VPP runs the distributed energy resources optimization, it informs all aggregated players about their scheduling accordingly to their DR contracts.

\section{CASE STUdy}

The following section presents the case study performed to implement the new structure of the SHIM platform developed in the context of the microgrid to obtain a energy efficiency management. The case study considers a 25-bus microgrid that includes a typical residential consumer located in GECAD laboratory. The results aim to show the increase of energy efficiency in a house management system, through communication with the several agents using the proposed ontology. The simulation of the case study is obtained through the following process:

- ERM platform in microgrid;

- Communication with house management system about scheduling consumption;

- Execution of the house management algorithm;

- Action on the loads using the PLC.

\section{A. Residential Microgrid Context}

The private distribution network used in the simulation is a real distribution network of a residential area located in Portugal, as shown in Fig. 3 [17]. The VPP operator manages 25 distributed generation units (Photovoltaic system), 5 external suppliers (main grid supply in bus 1), and 82 consumers with DR programs (load reduce program). A total of 24 lines with $1.65 \mathrm{~km}$ length represent the radial microgrid. The technical limits of the lines can be seen in [17]. Fig. 3 presents the diagram of the considered microgrid and Load 6 represents the real GECAD laboratory. 


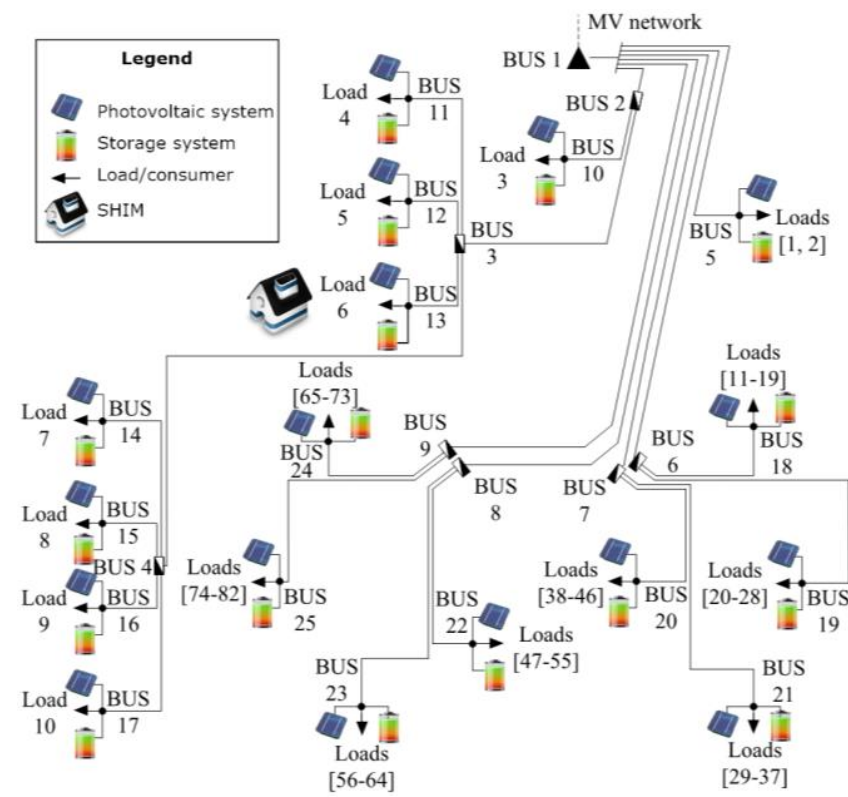

Figure 3. Case study microgrid of 25-bus

The presented case study considers a simulation day in winter profile in Portugal, namely 22nd January 2013 (Fig. 4). In this context, the photovoltaic generation reaches low values, insufficient to supply the expected loads consumption. Table I shows the residential microgrid characterization.

TABLE I. MICROGRID CHARACTERIZATION

\begin{tabular}{|c|c|c|c|c|c|}
\hline $\begin{array}{c}\text { Building } \\
\text { types }\end{array}$ & Qty & BUS & Description & Qty & $\begin{array}{c}\text { Energy } \\
(\text { kWh })\end{array}$ \\
\hline \multirow{3}{*}{$\begin{array}{c}\text { Residential } \\
\text { house }\end{array}$} & \multirow{3}{*}{8} & \multirow{3}{*}{$10-17$} & Load 3-10 & $\overline{8}$ & 73.96 \\
\hline & & & PV & 8 & 51.51 \\
\hline & & & Storage $^{\mathrm{a}}$ & 8 & 8.00 \\
\hline \multirow{3}{*}{$\begin{array}{c}\text { Residential } \\
\text { building }\end{array}$} & \multirow{3}{*}{8} & \multirow{3}{*}{$18-25$} & Load $11-82$ & 72 & 403.83 \\
\hline & & & PV & 8 & 104.56 \\
\hline & & & Storage $^{\mathrm{a}}$ & 8 & 24.00 \\
\hline \multirow{3}{*}{$\begin{array}{l}\text { Commercial } \\
\text { building }\end{array}$} & \multirow{3}{*}{1} & \multirow{3}{*}{5} & Load 1-2 & 2 & 242.87 \\
\hline & & & $\mathrm{PV}$ & 1 & 4.39 \\
\hline & & & Storage & 1 & 3.00 \\
\hline
\end{tabular}

The number of residential houses and buildings considered is 8 . The residential buildings connect 72 apartments, each one representing one consumer (Loads 11-72). The number of commercial buildings considered is 1 with 2 consumers (Loads 1-2). Residential houses are located in bus 10 to 17, whereas bus 13 (Load 6) is located the GECAD laboratory. Each residential house and building, and commercial building has one photovoltaic system and one storage system.

In this case, the photovoltaic system is a real installation in the roof of GECAD laboratory, being the generation profile saved in a database.
Table II presents the data of the energy resources that are managed by the VPP operator and the bid coefficients, expressed in monetary unit per $\mathrm{kWh}$, the maximum power limits and the location of resources.

TABLE II. ENERGY RESOURCES DATA

\begin{tabular}{|c|c|c|c|c|c|}
\hline \multirow{2}{*}{\multicolumn{2}{|c|}{ Energy resources }} & \multirow{2}{*}{ BUS } & \multicolumn{2}{|c|}{ Rated Power $(\mathrm{kW})$} & \multirow{2}{*}{$\begin{array}{c}\text { Prices } \\
(\mathbf{m} . \mathbf{u} . / \mathrm{kWh})\end{array}$} \\
\hline & & & Per BUS & Total & \\
\hline \multirow{3}{*}{\multicolumn{2}{|c|}{ Photovoltaic }} & 5 & 11.04 & 11.04 & \multirow{3}{*}{0.01} \\
\hline & & 2 to 10 & 3.68 & 29.44 & \\
\hline & & 19 to 25 & 11.04 & 88.32 & \\
\hline \multirow{5}{*}{\multicolumn{2}{|c|}{ External Supplier }} & & 0.50 & \multirow{5}{*}{53.50} & 0.12 \\
\hline & & & 1.00 & & 0.13 \\
\hline & & & 2.00 & & 0.14 \\
\hline & & & 30.00 & & 0.16 \\
\hline & & & 20.00 & & 1.00 \\
\hline \multirow{6}{*}{ Storage } & & 5 & 1.00 & 1.00 & \multirow{3}{*}{0.00} \\
\hline & Charge & 2 to 10 & 0.30 & 2.40 & \\
\hline & & 19 to 25 & 1.00 & 8.00 & \\
\hline & & 5 & 1.00 & 1.00 & \multirow{3}{*}{0.10} \\
\hline & Dischar & 2 to 10 & 0.30 & 2.40 & \\
\hline & & 19 to 25 & 1.00 & 8.00 & \\
\hline DR & Reduce & all & - & 139.14 & 0.01 \\
\hline
\end{tabular}

Fig. 4 presents the forecasted power demand and solar generation profile in the microgrid scenario. It can be seen that the peak load is expected at night periods (over than $52 \mathrm{~kW}$ ). The Load 6 is a consumer based in a typical residential consumer with the loads presented in GECAD laboratory. The general characteristics of loads are summarized in Table III.

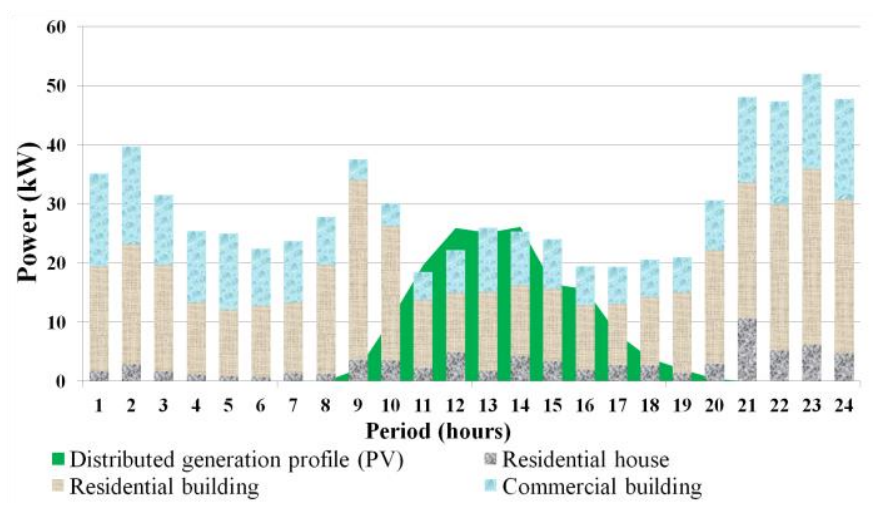

Figure 4. Power demand and solar generation profiles.

TABLE III. RESOURCES OF THE SIMULATED DOMESTIC CONSUMER

\begin{tabular}{c|c|c|c|c}
\hline \hline Loads & ID & House division & Type & Power $(\mathbf{k W})$ \\
\hline Light 1 & 1 & Hall & Real & 0.116 \\
\hline Light 2 & 2 & \multirow{3}{*}{ Room } & Real & 0.116 \\
\cline { 4 - 5 } Light 3 & 3 & Real & 0.116 \\
\cline { 4 - 5 } Window 1 & 4 & Real & 0.103 \\
\hline
\end{tabular}




\begin{tabular}{|c|c|c|c|c|}
\hline HVAC Ro & 5 & & Virtual & 0.910 \\
\hline TV Ro & 6 & & Virtual & 0.120 \\
\hline Light 4 & 7 & \multirow{9}{*}{ Kitchen } & Real & 0.116 \\
\hline Window 2 & 8 & & Real & 0.103 \\
\hline Microwave & 9 & & Virtual & 0.991 \\
\hline Water cooler & 10 & & Virtual & 0.545 \\
\hline Kettle & 11 & & Virtual & 2.280 \\
\hline Coffee machine & 12 & & Virtual & 1.300 \\
\hline Refrigerator & 13 & & Virtual & 0.130 \\
\hline Washing machine & 14 & & Virtual & 2.300 \\
\hline HVAC Ki & 15 & & Virtual & 1.000 \\
\hline Light 5 & 16 & \multirow{2}{*}{ Bathroom } & Real & 0.116 \\
\hline Water heater & 17 & & Virtual & 1.500 \\
\hline Light 6 & 18 & \multirow{6}{*}{ Living room } & Real & 0.116 \\
\hline Light 7 & 19 & & Real & 0.116 \\
\hline Light 8 & 20 & & Real & 0.116 \\
\hline Window 3 & 21 & & Real & 0.103 \\
\hline HVAC LV & 22 & & Virtual & 1.000 \\
\hline TV LV & 23 & & Virtual & 0.120 \\
\hline
\end{tabular}

To approximate the simulation of a real case, the domestic consumer simulated in SHIM is able to control real loads and virtual loads (according the item Type in the table) simulating the characteristics of the real ones. The loads like lights can be controlled directly by the SHIM through a panel interface and it is consider real loads. The virtual loads are implemented considering the data collected in real appliances and saved on database. The database can obtain the consumption profile of different loads such as refrigerators, microwaves, washing machines, and HVAC.

\section{B. Results}

The results of the case study present the scheduling of the ERM platform and the SHIM optimization. Fig. 5 presents the real-time scheduling results of the ERM concerning the energy use by the several resources managed by VPP operator in order to fulfill the consumption needs. To fulfill the goals of the VPP and satisfy the consumers, the operator needed to acquire: $67.95 \%$ of energy from external suppliers, even using all the energy produced by the photovoltaic systems; $1.16 \%$ of energy storage systems through the discharge and; $6.79 \% \mathrm{u}-$ sing DR programs during peak consumption periods. It was possible to sell $2.96 \%$ of energy to external suppliers.

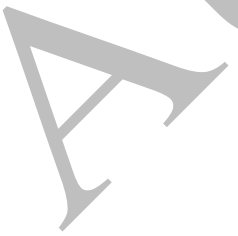

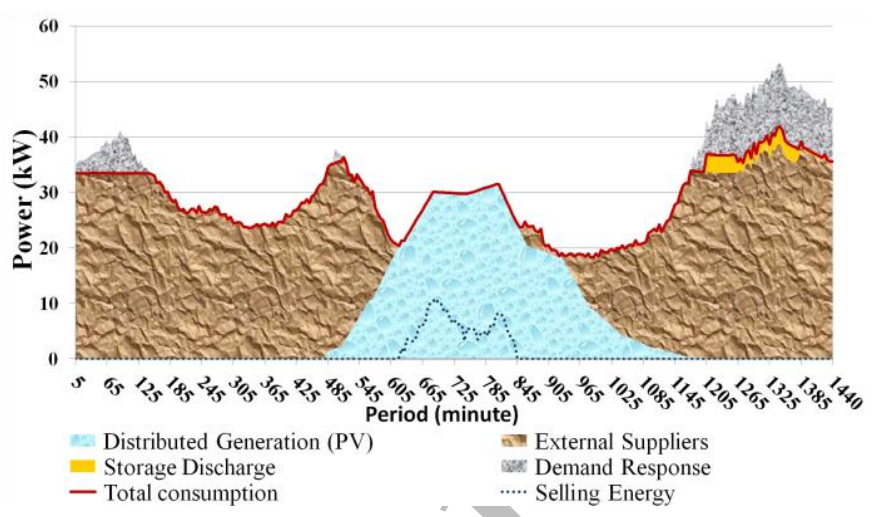

Figure 5. Real-time ERM results.

The consumption for Load 6 resulting from the scheduling of the VPP operator, can be seen in Fig. 6. The changes in the load forecasts for Load 6 resulted in the reduction of the energy supply during times of peak consumption. The real-time results show a reduction of $19.63 \%$ in the expected load.

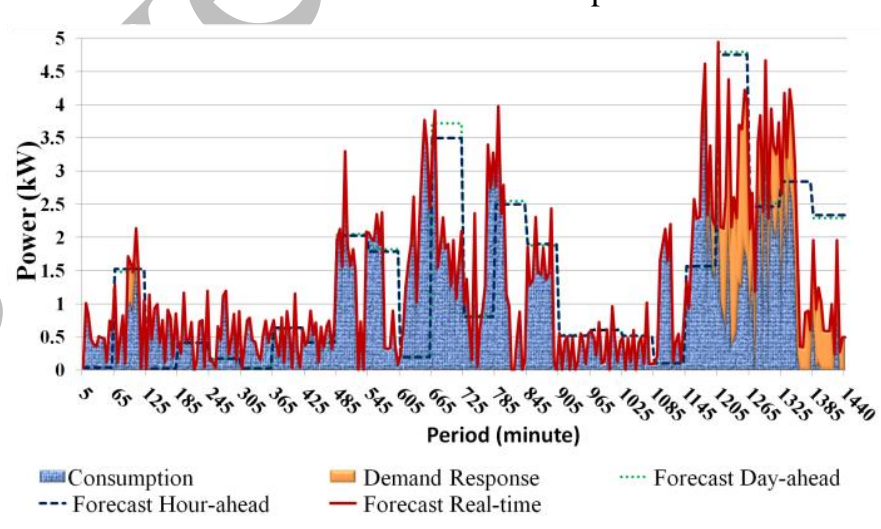

Figure 6. Consumption results for Load 6 (from ERM platform).

The SHIM system obtains the optimization results for each load according with the ERM limit indicated by the VPP operator. The ERM limit represents the difference between Consumption and DR, as seen in Fig. 6. The SHIM results for each device of Load 6 are presented in Fig. 7. A comparison to the ERM limit is also provided. Being a winter scenario, the HVAC and Water Heater assume higher priority for the optimization. Also it is also important to mention, for the interpretation of results, the capacity of lights to control the consumption through electronic ballasts. Results show that the optimization in the house was able to adapt the consumption in moments when DR events occur, for example, between the period 1205 and 1440 (peak consumption period - see Fig. 6). 


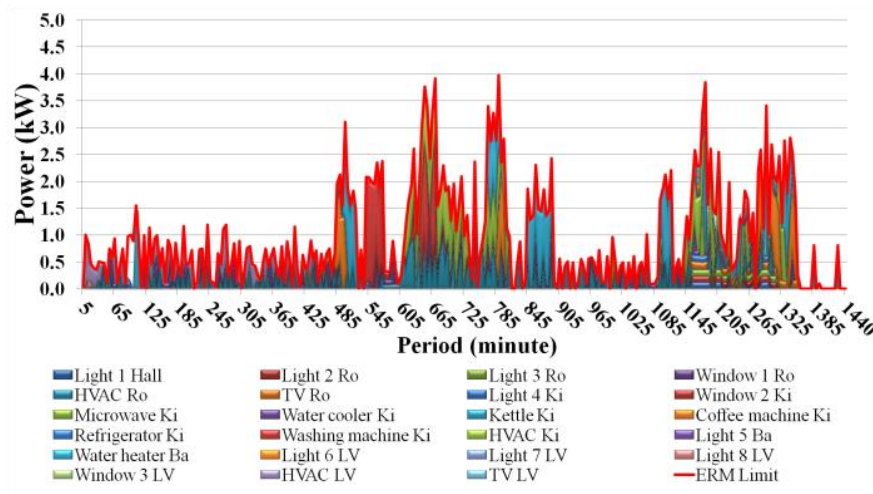

Figure 7. Optimization results obtained by the SHIM for Load 6.

If the case study contains a summer scenario, different conditions has been taking into account changing the priorities values to each load. For example, Water Heater can be represented by a lower priority for the SHIM system and the same happens with the lights due to the higher number of hours with luminosity. And in the case of ERM results, a summer scenario obtains higher number of sun hours which results in the higher power generated by photovoltaic system.

\section{CONCLUSIONS}

This paper presented a new approach for the house energy management, using ontologies to enable semantic communications between heterogeneous multi-agent entities, to support an efficient energy management of end consumers. The house management system operates according to a multi-agent based smart grid simulation platform, which uses an energy resources management model. The main goal is to obtain scheduling for real and virtual resources of the house, and the communication between heterogeneous agents in the SHIM system is performed by ontologies.

The presented paper is innovative and contributes to the following aspects: (i) restructuring of SHIM platform with the inclusion and application of ontologies; (ii) ontologies communication promotes the interoperability between heterogeneous agent's systems contributing to a more efficient management system; (iii) the house management system operates according to a multi-agent based smart grid simulation platform, using an energy resources management model that includes demand response programs, electric vehicles and several types of renewable energy sources.

Results show that the several agents of the presented system were able to communicate appropriately using the proposed ontologies, enabling an effective interaction between the diverse algorithms and operation levels. This way, a full communication flow all the way from the end-user devices to the smart grid operator is accomplished, allowing all information and intelligent methods to improve results on the entire chain. The future work proposed is the implementation of the new approach for the house energy management system in different types of consumers: office, commercial, industrial, among others, beholding also the multi-agent based smart grid simulation platform.

\section{References}

R. Wüstenhagen and E. Menichetti, "Strategic choices for renewable energy investment: Conceptual framework and opportunities for further research," Energy Policy, vol. 40, no. 1, pp. 1-10, 2012.

[2] Eurostat, "Smarter, greener, more inclusive? - Indicators to support the Europe 2020 strategy," Eurostat Flagship publication, 2015. [Online]. Available: http://ec.europa.eu/eurostat/de/web/productsstatistical-books/-/KS-EZ-14-001.

[3] L. Fernandes and P. Ferreira, "Renewable energy scenarios in the Portuguese electricity system," Energy, vol. 69, pp. 51-57, 2014.

[4] D. Carvalho, J. Wemans, J. Lima, and I. Malico, "Photovoltaic energy mini-generation: Future perspectives for Portugal," Energy Policy, vol. 39, no. 9, pp. 5465-5473, 2011.

[5] G. Brusco, A. Burgio, D. Menniti, A. Pinnarelli, and N. Sorrentino, "Energy management system for an energy district with demand response availability," IEEE Trans. Smart Grid, vol. 5, no. 5, pp. 2385-2393, 2014.

[6] J. Guerrero, F. Blaabjerg, T. Zhelev, K. Hemmes, E. Monmasson, S. Jemei, M. Comech, R. Granadino, and J. Frau, "Distributed Generation: Toward a New Energy Paradigm," IEEE Ind. Electron. Mag., vol. 4, no. 1, pp. 52-64, Mar. 2010.

[7] J. Ye, Q. Xie, Y. Xiahou, and C. Wang, "The research of an adaptive smart home system," in 2012 7th International Conference on Computer Science \& Education (ICCSE), 2012, pp. 882-887.

[8] P. Faria and Z. Vale, "Demand response in electrical energy supply: An optimal real time pricing approach," Energy, vol. 36, no. 8, pp. 5374-5384, 2011.

[9] J. Y. Son, J. H. Park, K. D. Moon, and Y. H. Lee, "Resource-aware smart home management system by constructing resource relation graph," IEEE Trans. Consum. Electron., vol. 57, no. 3, pp. 1112$1119,2011$.

[10] F. Fernandes, H. Morais, Z. Vale, and C. Ramos, "Dynamic load management in a smart home to participate in demand response events," Energy Build., vol. 82, pp. 592-606, Oct. 2014.

[11] S. Borlase, Smart Grids: Infrastructure, Technology, and Solutions. 2012.

[12] L. Gomes, P. Faria, H. Morais, Z. Vale, and C. Ramos, "Distributed, agent-based intelligent system for demand response program simulation in smart grids," IEEE Intell. Syst., vol. 29, no. 1, pp. 56-65, 2014.

[13] M. Silva, H. Morais, T. Sousa, P. Faria, and Z. Vale, "Timehorizont distributed energy resources scheduling considering the integration of real-time pricing demand response," PowerTech, 2015 IEEE Eindhoven. pp. 1-6, 2015.

[14] M. Silva, T. Sousa, H. Morais, and Z. Vale, "Real-Time Energy Resource Scheduling Considering a Real Portuguese Scenario," in Proceedings of the 19th IFAC World Congress, 2014, 2014, pp. 2267-2272.

[15] P. Alexopoulos, K. Kafentzis, C. Zoumas, "ELMO: An Interoperability Ontology for the Electricity Market," in Proceedings of the International Conference on e-Business, Milan, Italy, July 7-10, 2009.

[16] K. Dam and J. Keirstead, "Re-use of an ontology for modelling 
urban energy systems," in Proceedings of the 3rd International Conference on Infrastructure Systems and Services: Next Generation Infrastructure Systems for Eco-Cities (INFRA), Shenzhen, China, 11-13 November 2010.
B. Canizes, M. Silva, P. Faria, S. Ramos, and Z. Vale, "Resource scheduling in residential microgrids considering energy selling to external players," Power Systems Conference (PSC), 2015 Clemson University. pp. 1-7, 2015. 